Original Research Paper

\title{
Stock Return, Growth and Inflation in India: Analysis of Stochastic Seasonality, Impulse Response and Multivariate GARCH
}

\author{
Panchanan Das \\ Department of Economics, University of Calcutta, India
}

\author{
Article history \\ Received: $18-08-2020$ \\ Revised: $20-10-2020$ \\ Accepted: 09-11-2020 \\ Email: pdeco@caluniv.ac.in
}

\begin{abstract}
This study analyses the empirical interdependence among asset returns, industrial growth and inflation after controlling for interest rate by considering stochastic seasonality and conditional volatility with monthly time series in India. The HEGY unit root test suggests that industrial growth and inflation experience only stochastic trend and no persistent stochastic behaviour at any other seasonal frequencies, while stock return follows persistent seasonal trend. The study observes that causality goes from stock return to industrial growth, although the extent of causality is very low, but not the other way round. This finding has significant policy implications particularly in the context of financial sector reforms in India. Inflation has negative impact on stock returns, while the innovations in stock returns have not transmitted to inflation.
\end{abstract}

Keywords: Seasonal Time Series, Business Cycles, Stock Return, Economic Growth, India JEL Classification Codes: C32, E32, E44, O40, 053

\section{Introduction}

The role of the financial system is essential for a country's economic growth. This articulation was developed long years back by (Bagehot, 1873) who argued the role of finance in facilitating industrial revolution of Great Britain. Later on, this argument has been extended further by (Hicks, 1969; Goldsmith, 1959; Levine, 1991) and many other scholars by considering different dimensions of finance including a variety of financial instruments like bank credit, demand deposits, stocks, bonds and derivative securities. In another views, (Robinson, 1952) and (Lucas Jr, 1988) among others asserted that a country's financial system automatically responds to demand for particular types of financial arrangements induced by economic growth. In Keynes, the stock market is treated as a Casino and finance has little relevance in country's growth. Stiglitz (1993) argued that stock market fails to enhance corporate governance. Thus, the link between financial development and real sector performance is not unambiguous in the literature.

The role of the financial market in explaining economic growth has been established in the literature by assuming that equity and debt financing are not perfect substitute. In presence of asymmetric information and uncertainty, equity financing can mitigate the conflicts of interest between different stakeholders within a firm and reduce agency costs. Stock market promotes initial fund needed for a project, risk diversification by spreading widely the ownership of the project, allocation of capital to productive use, liquidity and information that can accelerate long-run growth (Levine, 1991; Obstfeld, 1992).

This study examines the relation between return from the financial assets like stock, share or bond and industrial growth with monthly time series data from India by looking into stochastic seasonality and the behaviour of volatility clustering of the variables. Investigation of the relationship between stock return and real sector growth has been popularised since the publication of (Fama, 1981). The empirical evidence regarding the dynamic interaction among the financial and real sector variables is not unambiguous till today and we need to re-examine this relation to verify the relevance of modern business cycle hypothesis in the context of financial development of a transitional developing economy like India. The objective is to reconcile the dynamics observed in a transitional developing economy with the empirical regularities as observed in the literature based on data from the developed world. We have looked into whether the shocks in stock returns have had any effect on industrial growth and inflation and, also how stock returns 
response to innovations in the real sector in the context of financial sector reforms in India.

In (Fama, 1981), the negative relation between inflation and stock return was linked to the inverse relationship between inflation and real output by assuming that money demand is pro-cyclical. Later on, more attempts have been done by the scholars to reexamine the issue with different dataset by applying different methodologies under different assumptions. For example, (Geske and Roll, 1983) assumed countercyclical effects of monetisation of government deficits to establish negative relation between asset returns and inflation. Lee (1992) documented that stock returns have significant effects on real activity but a little effect on inflation by using a Vector Auto Regression (VAR) model during the post-war period. Marshall (1992) observed that stock return and inflation are negatively related under the condition that inflation is strongly related to real economic activity. Hess and Lee (1999) estimated the relation between stock return and inflation by incorporating supply shocks to the real sector and demand shocks originated through the money supply and found similar results as in (Marshall, 1992). Kim and in (2005) tested Fisher hypothesis for risky asset by using wavelet multiscaling method and observed a positive relationship between stock returns and inflation during the extreme periods (1-month period and 128month period), while a negative relationship at the intermediate periods in the sample.

In India, the empirical research on stock return and growth by following the legacy of (Fama, 1981) is very much limited. Nagaraj (1996) by using Indian data examined the growth behaviour of India's capital market to find out the role of the stock market in financing capital to industry. The study observed an increasing role of stock market after 1991 on industrial growth because of the financial sector reform, although the performance was not significant during the pre-reform period. Bhattacharya and Sivasubramanian (2003) observed that GDP growth is led by the financial sector development, but not the other way round. Acharya et al. (2009) investigated the link between financial development and economic growth in India by using state level data for the time period of 1981 to 2002 and observed a long-run relationship between them. Gupta and Padhan (2007) carried out similar work by using monthly data on index of industrial production and Sensex during 1991 to 2005 and observed a bi-directional relationship between them. Deb and Mukherjee (2008) used quarterly data on real GDP, market capitalisation and stock market volatility for the period of 1996 to 2007 to estimate the relationship between stock market development and economic growth in India and observed a bi-directional relationship between market capitalisation and economic growth.

In this study we revisit the relationship between stock return and inflation as well as stock return and industrial growth by analysing seasonality and unit roots at monthly seasonal frequencies with Indian data in a framework of unrestricted VAR model. Analysis of peaks and trenches of macroeconomic variables within a year provide a lot of information on many macroeconomic issues. The development of stock market activities and financial market openness in India since the early $1990 \mathrm{~s}$ has made a dramatic change in the behaviour of stock returns. We use volatility clustering model to capture the volatile behaviour of stock return in analysing the relationship between stock return and the real sector performance. First, we examine the stochastic seasonality of the monthly series of stock return, index of industrial production, inflation and interest rate by carrying out seasonal unit root tests at different frequencies. Second, we analyse the relationship between return and growth, as well as between return and inflation in a VAR framework. The extent and direction of transmission of shocks in return in the Bombay Stock Exchange, industrial growth and inflation rate is examined by using impulse response function. Third, we incorporate stock market volatility and the time dependent variability in growth and inflation in the framework of multivariate GARCH model to look into the time varying pattern of volatility experienced by the series and how the return-growth and return-inflation relationships have been affected after incorporating the volatile behaviour of the variables.

The primary objective of this study is to find out the causality between stock return and industrial growth. We observe that causality goes from stock return to industrial growth, but the extent of causality is very low. This finding has significant policy implications particularly in the context of financial sector reforms in India. This study also observes that inflation has negative impact on stock returns following the hypothesis put forward by Fama (1981). The rest of the study is organised as follows.

\section{Relation between Growth and Return- Neoclassical Views}

Economic growth is determined primarily by productivity growth and employment growth. Asset returns, on the other hand, are determined by time preference, the intertemporal elasticity of substitution in consumption and attitudes toward risk. Apparently, 
although the determining factors of growth and asset returns are different, they are well connected both in the theoretical as well as empirical literature.

Investments by the firms in excess of own capital to meet the project costs determines primarily the equity values in the financial market. In this capital expenditure theory in finance, increases in output raise average real rates of return on capital which induces more capital expenditure. In capital expenditure theory, the assumption that financial market is able to make rational forecast of the real sector is the basis for approximating a positive relationship between stock return and output growth. Investors in the stock market make investment decisions by anticipating changes in the real sector activities. Better performance in the real sector is reflected in higher return and lower inflation. This results in a direct relationship between stock returns and real output and an inverse relationship between stock returns and inflation.

The stock market becomes more active in providing funds to corporate enterprises as the financial system develops in an economy. The corporate entrepreneurs can collect funds in excess of its own capital by issuing initial public offering in the form of equity shares, preference share or debentures in the primary market. The secondary market becomes effective in the stock market after issuing initial public offering. Transactions of equity shares take place through brokers in the secondary market where individual investors receive return in the form of a change in equity price. Equity price will rise and the return will be more if corporate entrepreneurs issuing the equity perform well. In this way the real sector performance transmits into stock returns. A good performer is rating well by the credit rating agencies and in this case the entrepreneur can raise its funds for further expansion easily from the market.

The basic framework of neoclassical growth models (Solow, 1956; Ramsey, 1928; Diamond, 1965) suggest that gross returns from capital is proportional to the rise in growth. These models provide some economic reasons to explain why economic growth is positively related to asset returns. In the Solow growth model, for example, as the saving rate is fixed, faster population growth lowers the steady-state capital-labour ratio, which in turn means a higher marginal product of capital. PostKeynesian theories of business cycles and growth, on the other hand, focused on aggregate demand in analyzing the contradiction between growth and distribution (Kaldor, 1940; Goodwin, 1967; Kalecki, 1968; von Arnim and Barrales, 2015) and these theoretical frameworks would also be useful in examining the relationship between financial development and growth in a country like India.

Theoretically, positive stock return is an indicative to accelerating economic growth and negative return associates with potential economic recession. The statistical regularities indicating a strong relationship between stock market performance and growth have been well established in the literature for developed countries (Dailami and Aktin, 1990; Levine and Zervos, 1996; Alam and Hasan, 2003; Brasoveanu et al., 2008; Vazakidis and Adamopoulos, 2011; Oskooe, 2010). A well-developed stock market can allocate capital resources to productive investments efficiently, which would eventually promote economic growth (Dailami and Aktin, 1990). Alam and Hasan (2003) observed that the stock market development has favourable effect on economic growth in the us. By using data for France for the period of 1965 to 2007, (Vazakidis and Adamopoulos, 2011) estimated the relation between stock market development and economic growth by applying vector error correction model and observed a positive association from economic growth to stock market development. Oskooe (2010) investigated the relationship between stock market performance and economic growth in Iran by using real GDP and stock price indices for the period of 1997 to 2008 and found that long run growth has influence on stock price movements and in the short run, stock price influences economic growth.

The theoretical models, however, are oversimplified and fail to capture investors' behaviour and institutional characteristics properly, particularly in transitional developing countries. Also, as the financial market in the transitional developing world is not well developed, one cannot expect a strong link between stock return and growth as observed in the developed world. Whether performance of stock market is associated with economic growth in developing countries has been a cause of concern since last few decades back. The expansion of market capitalisation in stock markets in emerging economies is almost three times larger than expansion of market capitalization in the developed stock markets (El-Wassal, 2005). But whether stock market can predict the economic growth or vice versa in transitional economy is still debating in the literature. Empirical findings of cross-country growth regression by (Levine and Zervos, 1996) suggest that stock market development is positively and strongly associated with long-run economic growth. Har et al. (2008) tested the causal relationship between stock market and economic activity in Malaysia for the period of 1977 to 2006 and observed that causality runs from stock market to economic activity and not the other way around.

In India, significant development is observed in stock market since the early $1990 \mathrm{~s}$ after opening of the financial market and debate has been commencing on the role of stock market development in promoting economic growth or vice versa. The inflow of foreign institutional investments have been allowed directly onto the Indian stock markets since the early 1990 s. The opening of the domestic financial market is expected to increase competition as well as volatility in the Indian stock market. Financial innovations and regulatory 
reforms by the SEBI have brought a significant structural transformation in the stock market in India. Financial sector reforms brought expansion of the Indian stock market in terms of number of listed companies, number of shareholders and market capitalisation. This kind of financial development has important implications for macroeconomic performance in the Indian economy.

\section{Data and Variables}

This study is based on monthly time series of stock return, industrial growth rate, inflation rate and interest rate for a period of 27 years, from April 1993 to April 2020, in India. Sensex in Bombay Stock Exchange (BSE) is available in daily frequency in the form of opening value, closing value, high value and low value in a day. We have used closing value of Sensex to calculate stock return. As the real variables like index of industrial production (iip), wholesale price index (wpi) and the call money rate are available in monthly frequency in the official statistics in India, we have converted closing values of Sensex from daily to their monthly averages. Asset return is calculated by taking difference in closing values of Sensex between two consecutive time points. The iip and wpi have been compiled and published by the Central Statistics Office (CSO) on monthly basis. Currently, these series are available at 2011-12 base year prices. In constructing these series, CSO has changed the base year on the basis of National Sample Survey (NSS) household consumer expenditure survey year and, in earlier period, on the basis of census year to accommodate new items and to discard the outdated once. Thus, in official statistics there exists different series of iip and wpi for different base years. We have constructed back series at 2011-12 base year by applying splicing method to have longer time series for iip and wpi. The iip shows a summary trend in industrial output comprising of nearly 700 items from mining, manufacturing and electricity. Industrial growth rate is calculated by taking first difference of log values of iips and inflation rate is obtained from the first difference of log values of wpi. The monthly weighted call money rate published by the Reserve Bank of India (RBI) is used as a proxy for interest rate.

\section{Econometric Models}

Stochastic seasonality cannot be ruled out in the real sector and financial activities. The seasonal pattern of economic time series may be stochastic because of weather and many other events affecting the series which are not observable. Some stochastic components have temporary effects, while some other types of stochastic components have long lasting effects on the future values of the series. For example, technological innovations in industrial activities may spread over several periods and its effect will be long lasting, while the effects of weather are expected to be temporary in nature. It is important to separate out the effects originated from innovation from those generated by the change in deterministic seasonal pattern.

To discriminate between deterministic and stochastic behaviour of seasonality, we have used HEGY test for seasonal unit roots developed in (Hylleberg et al., 1990). Although this test was developed initially to deal with quarterly data on income and consumption in the UK, it has been extended further for using monthly frequency of data (Franses, 1991; Taylor, 1998; Mugambe and Reilly, 2007; de Pablo Valenciano et al., 2008). To carry out the HEGY tests, we have, first, to detrend the data such that the tests become invariant to the parameters involved in the deterministic part. In this study we detrend the series $y_{t}$ by applying OLS.

The augmented regression equation with the detrended monthly series, $\tilde{y}_{t}$, as used in HEGY test is:

$$
\begin{aligned}
& \Delta_{12} \tilde{y}_{t}=\pi_{0} \tilde{y}_{0, t}+\pi_{6} \tilde{y}_{6, t}+\sum_{i=1}^{5}\left(\pi_{1 i} \tilde{y}_{1 i, t}+\pi_{2 i} \tilde{y}_{2 i, t}\right) \\
& +\sum_{j=1}^{p} \tau_{j} \Delta_{12} \tilde{y}_{t-j}+\varepsilon_{t}
\end{aligned}
$$

Here:

$$
\begin{aligned}
& \tilde{y}_{0, t}=\tilde{y}_{t-1}+\tilde{y}_{t-2}+\cdots \ldots \ldots+\tilde{y}_{t-11}+\tilde{y}_{t-12} \\
& \tilde{y}_{0, t}=-\tilde{y}_{t-1}+\tilde{y}_{t-2}+-\ldots \ldots .+\tilde{y}_{t-11}+\tilde{y}_{t-12} \\
& \tilde{y}_{1 i, t}=\sum_{m=0}^{11} \cos \{(m+1) 6 \pi i\} \tilde{y}_{t-m-1}, \\
& \tilde{y}_{2 i, t}=-\sum_{m=0}^{11} \sin \{(m+1) 6 \pi i\} \tilde{y}_{t-m-1}
\end{aligned}
$$

For monthly data:

$$
i=1,2, \ldots, 5 ; m=0,1, \ldots \ldots, 11
$$

The lag length $p$ is used in augmented terms to control for serial correlation in the error term, $\varepsilon_{t}$. The optimum lag length is determined by following Modified Akaike Information Criterion (MAIC).

The HEGY test is a joint test for non-seasonal or long run or zero frequency unit roots and seasonal unit roots. The null hypothesis is that the variable contains a unit root at that frequency and the alternative is that the variable was generated by a stationary process.

In looking at the behaviour of seasonality we test the following hypotheses.

Hypothesis 1:

$H_{0,0}: \pi_{0}=0$
$H_{1,0}: \pi_{0}<0$ 
Hypothesis 2:

$H_{0,6}: \pi_{6}=0$

$H_{1,6}: \pi_{6}<0$

Hypothesis 3:

$H_{0, I}: \pi_{1, i}=0, \pi_{2, i}=0$

$H_{1}: \pi_{1 i} \neq \pi_{2 i} \neq 0$

The first hypothesis is associated with the zero frequency for testing unit root for the longer period, the second one considers half seasonal duration associated with the Nyquist frequency $(\pi)$, while the third one is associated with the seasonal harmonic frequencies. The HEGY test is more flexible than the Dickey-Fuller test because it entails testing for unit roots at different frequencies of the series. In HEGY test, neither the standard t-distribution nor the Fdistribution are used for critical values because the series contains unit root under null hypothesis. For monthly data, (Beaulieu and Miron, 1993) tabulated the critical values for the tests for different frequencies.

After analysing the stochastic nature of seasonality of the variables, to find out the nature of transmission of the shocks between stock return and industrial growth we have used reduced form of unrestricted VAR with 4 variables, namely, stock return, industrial growth, inflation rate and monthly weighted call money rate. The Schwarz information criterion is used to determine the optimum lag length included in the VAR model.

For robust estimation, the VAR system must be stationary around deterministic trend. We find out the order of integration of each of the variables of the system by applying HEGY test as described above and accordingly transform the variables by taking appropriate order of differences to have stationarity.

Let the VAR model in reduced form is specified as:

$$
Y_{t}=\Pi_{0}+\Pi_{1} Y_{t-1}+e_{t}, e_{t} \sim(0, \Omega)
$$

Here, $Y_{t}$ is a $4 \times 1$ vector of the endogenous variables used in this study, the covariance matrix, $\Omega$, is positive definite.

The conditional mean, $E\left(Y_{t} \mid Y_{t-1}\right)=\Pi_{0}+\Pi_{1} Y_{t-1}$, can be interpreted as the agent's plan at time $t$ given the past information of the process. The assumption that white noise innovation implies that agents are rational in a sense that the deviation between the actual outcome $Y_{t}$ and the plan is transitory. The white noise assumption of the residuals is crucial for meaningful statistical inference as well as for economic interpretation of the model as a description of the behaviour of rational agents.

By introducing lag operator, the reduced form of a VAR is expressed as:
$\left(I-\prod_{1} L\right) Y_{t}=\prod_{0}+e_{t}$

or:

$Y_{t}=A+\sum_{i=0}^{\infty} \prod_{1}^{i} e_{t-1}$

The stationarity restrictions require that the eigenvalues of $\left|\Pi_{1}-\lambda I\right|=0$ are less than unity in absolute sense and under these restrictions VAR (1) is expressed as vector moving average of order infinity, VMA $(\infty)$, as shown in Eq. (7), which could be used to find out the impulse response function. The VMA $(\infty)$ representation in the form of impulse response function is very much useful for analysing the effects of external shocks. In this study the dynamic interdependence of the system is examined by using the impulse response.

In reduced form VAR, the random error, $e_{t}$, is not orthogonal. Suppose that the square matrix, $M$, makes the shocks in the reduced form VAR orthonormal, or uncorrelated across each other and with unit variance:

$\varepsilon_{t}=M_{e_{t}}$

and:

$E\left(\varepsilon_{t} \varepsilon_{t}^{\prime}\right)=I$

Here, $\mathrm{MM}=\Omega^{-1}$

In terms of these orthogonal errors, the VMA could be expressed as:

$Y_{t}=A+\sum_{i=0}^{\infty} \Phi_{1}^{i} \varepsilon_{t-i}$

The $(j, l)_{\text {th }}$ element of $\Phi_{1}^{i}$, the $4 \times 4$ matrix in our case, is:

$\phi_{j l}^{(i)}=\frac{\delta x_{j, t+i}}{\varepsilon_{l t}}=\frac{\delta x_{j t}}{\delta \varepsilon_{l, t-i}}$

The elements $\phi_{j l}^{(i)}$ are called the Impulse Response Function (IRF), or the dynamic multiplier. The elements $\phi_{j l}^{(0)}$ are the impact multipliers. For example, $\phi_{12}^{(0)}$ measures the instantaneous impact of unit change in $\varepsilon_{2 \mathrm{t}}$ on $x_{1 \mathrm{t}}, \phi_{11}^{(1)}$ is the one period response of $\varepsilon_{1 t-1}$ on $x_{1 t}$, $\phi_{12}^{(1)}$ is the one period response of $\varepsilon_{2 t-1}$ on $x_{1 t}$ and so on.

The variance of the error terms may be the key issue of empirical research in many situations. The random error may reasonably be larger for some points or ranges of the data than for others and the data suffer from heteroscedasticity. We extend the empirical exercise by 
considering that the conditional variances of the variables in the VAR system follow an ARMA process. Bhowmik and Wang (2020) reviewed extensively the literature on the application of GARCH model in analyzing volatility in stock market return. Forecasting stock market volatility in a perfect way is indeed a difficult task and a large variety of GARCH model appears in the literature. To capture this effect we use multivariate Generalised Autoregressive Conditional Heteroscedastic (GARCH) model.

Multivariate GARCH model allows the conditional covariance matrix of the dependent variables to follow a flexible dynamic structure and allow the conditional mean to follow a Vector-Autoregressive (VAR) structure:

$Y_{t}=\beta^{\prime} Y_{t-1}+\varepsilon_{t}$

$\varepsilon_{t}=\Omega_{t}^{1 / 2} u_{t}$

where:

$Y_{\mathrm{t}}=$ An $4 \times 1$ vector of dependent variables

$\beta=$ An $4 \times 1$ vector of parameters

$\Omega_{t}^{1 / 2}=$ The Cholesky factor of the time-varying conditional covariance matrix $\Omega_{t}$ which is positive definite

$u_{\mathrm{t}}=$ An $4 \times 1$ vector of zero-mean, unit-variance and independent and identically distributed innovations

A multivariate GARCH model with one ARCH term and one GARCH term is specified as:

$$
\operatorname{vech}\left(\Omega_{t}\right)=\Pi+\Theta \operatorname{vech}\left(\varepsilon_{t-1} \varepsilon_{t-1}^{\prime}\right)+\operatorname{Bvech}\left(\Omega_{t-1}\right)
$$

Here, $\Pi$ is a vector of parameters and $\Theta$ and $B$ are conformable matrices of parameters. Restrictions are needed on $\Pi, \Theta$ and $B$ to ensure that $\Omega_{t}$ is positive definite for all $t$. In this study we apply the constant conditional correlation model developed by Bollerslev (1990).

The conditional correlation model uses nonlinear combinations of univariate GARCH models. In this model, $\Omega_{t}$ is decomposed into a matrix of conditional correlations $R_{\mathrm{t}}$ and a diagonal matrix of conditional variances $D_{\mathrm{t}}$ :

$\Omega_{t}=D_{t}^{1 / 2} R_{t} D_{t}^{1 / 2}$

In constant conditional correlation model the correlation matrix is time invariant:

$\sigma_{i j, t}^{2}=\rho_{i j} \sigma_{i t} \sigma_{t j}$

The parameters of this model are estimated by maximum likelihood, assuming that the errors follow a multivariate normal distribution.

\section{Empirical Results}

Seasonal fluctuations are an integral part of economic data and we should not ignore them in economic analysis. In this study we analyse the relationship between stock return and industrial growth and also between stock return and inflation after controlling for interest rate in a multivariate framework with monthly series of stock return, inflation, industrial growth and call money rate in India. Figure 1 shows that the series may contain the long-run and seasonal components and thus, they are likely to be integrated on zero and some seasonal frequencies. The economics behind the seasonal and non-seasonal movements depend on a large number of factors as revealed in the underlying theories.

\section{Seasonal Unit Roots}

Seasonality is a distinctive feature of many time series in the real sector like industrial growth as well as in financial time series and seasonal variation may be useful in explaining some parts of the variation observed in the series. We perform HEGY test for seasonal unit root by using the methodology developed in (de Pablo Valenciano et al., 2008). The estimated coefficients of Eq. (1), excepting for the augmented terms, attached with the 4 time series variables of monthly frequency used in this study and the estimated statistics for HEGY test are shown in Table 1. By using $t$ and $F$ distribution we reject the null hypothesis for testing significance of the model shown in Eq. (1) for each variable.

The test statistics shown in the middle part of Table 1 indicate that industrial growth, inflation and call money rate exhibit non-seasonal unit roots at zero frequency representing long run stochastic trend. Stock return, on the other hand, exhibits no unit root at frequency zero suggesting that the series has no pure trend. The absence of zero frequency unit root in the monthly series of stock return is consistent with the market efficiency hypothesis. To perform unit root tests at frequency 0 and frequency $\pi$ we need to use $t$ type distribution which are the left tail tests. The presence of unit root at frequency zero is associated with pure trend behaviour showing oscillations that need infinity periods to complete a cycle. In the case of testing unit root at frequency $\pi$, total number of cycles in a year is 6 implying that the series needs 2 months to complete a cycle. This type of seasonal behaviour is rejected for industrial growth and inflation, but not to be rejected for stock return and call money rate. 

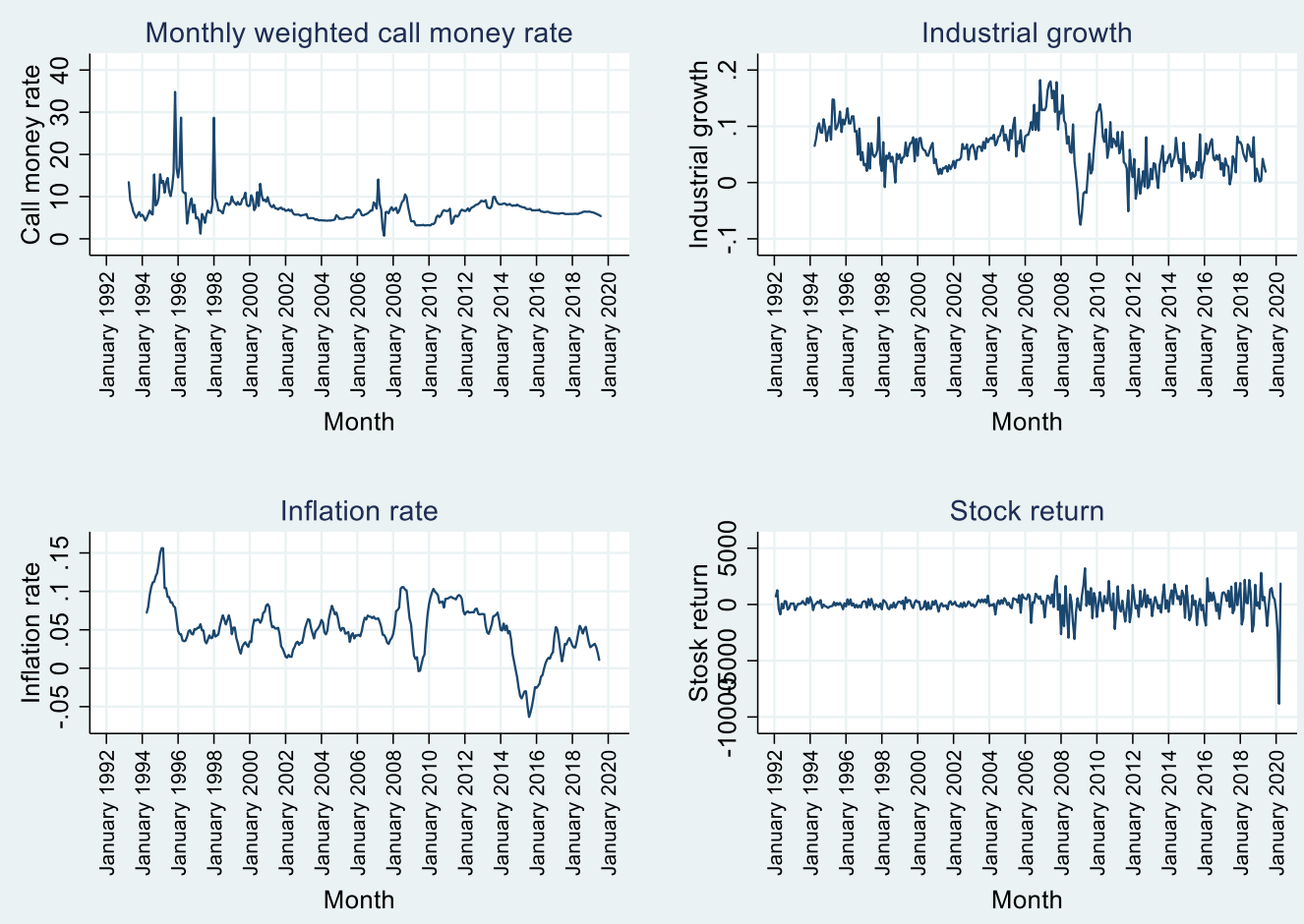

Fig. 1: Seasonal pattern of call money rate, industrial growth, inflation and stock return. Source: (RBI, 2020), Handbook of Statistics on Indian Economy

Table 1: Estimated statistics of HEGY test for seasonal unit roots

\begin{tabular}{|c|c|c|c|c|}
\hline Coefficients & Industrial growth & Inflation & Stock return & Call money \\
\hline$\pi_{0}$ & $-0.01278^{*}$ & $-0.00364 *$ & $-0.17276^{* * *}$ & $-0.01786^{*}$ \\
\hline$\pi_{6}$ & $-0.21338 * * *$ & $-0.52409 * * *$ & $-0.17192 * * *$ & $-0.10556 * *$ \\
\hline$\pi_{11}$ & $-0.10705 * *$ & -0.00662 & $-0.24701 * * *$ & $-0.14522 * * *$ \\
\hline$\pi_{21}$ & $-0.18118 * * *$ & $-0.10110 * * *$ & 0.09671 & $-0.10893 * *$ \\
\hline$\pi_{12}$ & $-0.26013 * * *$ & -0.00520 & $-0.19889 * * *$ & $-0.23796 * * *$ \\
\hline$\pi_{22}$ & $-0.17603 * *$ & $-0.23115 * * *$ & 0.06789 & $-0.09202 *$ \\
\hline$\pi_{13}$ & $-0.44244 * * *$ & $-0.19671 * *$ & $-0.12210 * *$ & $-0.25822 * * *$ \\
\hline$\pi_{23}$ & -0.09878 & $-0.51086 * * *$ & -0.04743 & -0.06877 \\
\hline$\pi_{14}$ & $-0.40656 * * *$ & $-0.38098 * * *$ & $-0.19054 * * *$ & $-0.23404 * * *$ \\
\hline$\pi_{24}$ & -0.03153 & $-0.55855 * * *$ & $-0.14334 * *$ & $-0.11124 *$ \\
\hline$\pi_{15}$ & $-0.47082 * * *$ & $-0.64150 * * *$ & $-0.18211 * * *$ & $-0.33905 * * *$ \\
\hline$\pi_{25}$ & -0.07863 & $-0.28370 * *$ & -0.05145 & 0.03787 \\
\hline \multicolumn{5}{|l|}{ Test statistics } \\
\hline $\mathrm{t}\left[\pi_{0}\right]$ & -2.578 & -2.259 & $-4.45 * * *$ & -2.447 \\
\hline $\mathrm{t}\left[\pi_{i}\right]$ & $-5.449 * * *$ & $-6.265 * * *$ & -3.70 & -2.977 \\
\hline $\mathrm{F}\left[\pi_{\mathrm{i}} / 6\right]$ & $18.571 * * *$ & $21.092 * * *$ & $13.589 * * *$ & $16.439 * * *$ \\
\hline $\mathrm{F}\left[\pi_{i} / 3\right]$ & $19.376^{* * *}$ & $25.134 * * *$ & 6.677 & $20.711 * * *$ \\
\hline $\mathrm{F}\left[\pi_{i} / 2\right]$ & $29.002 * * *$ & $38.058 * * *$ & 5.449 & $25.843 * * *$ \\
\hline $\mathrm{F}\left[2 \pi_{i} / 3\right]$ & $28.464 * * *$ & $30.893 * * *$ & $15.707 * * *$ & $14.297 * * *$ \\
\hline $\mathrm{F}\left[5 \pi_{i} / 6\right]$ & $33.907 * * *$ & $23.73 * * *$ & $9.226 *$ & $16.114 * * *$ \\
\hline F[All seas] & $31.823 * * *$ & $30.223 * * *$ & $11.641 * * *$ & $19.68 * * *$ \\
\hline F[All $]$ & $30.212 * * *$ & $29.318 * * *$ & $12.345^{* * *}$ & $18.919 * * *$ \\
\hline$N$ & 278.000 & 278.000 & 312.000 & 291.000 \\
\hline$R^{2}$ & 0.869 & 0.976 & 0.616 & 0.747 \\
\hline Adj $R^{2}$ & 0.842 & 0.972 & 0.542 & 0.695 \\
\hline
\end{tabular}

Source: Author's estimate with monthly series taken from (RBI, 2020) 
The seasonal unit root tests at other frequencies in HEGY use $F$ statistics and all are the right tail tests. The $F$ tests at frequencies $\frac{\pi}{6}, \frac{\pi}{3}, \frac{\pi}{2}, \frac{2 \pi}{3}, \frac{5 \pi}{6}$ capture the seasonal behaviour of the series with cycles of periods $12,6,4,3$ months and 12/5 months respectively within a year. The seasonal behaviour of these types is rejected for the monthly series of industrial growth, inflation and call money rate. But, the monthly series of stock returns contains two complex conjugate unit roots at frequencies $\frac{\pi}{3}$ and $\frac{\pi}{2}$ exhibiting a complex type of seasonal behaviour with seasonal oscillations that need 6 and 4 months respectively to complete a full cycle during a year.

Thus, the HEGY unit root test suggests that industrial growth and inflation experience only stochastic trend and no persistent stochastic behaviour at any other seasonal frequencies. Call money rate, however, exhibits stochastic trend and persistent seasonal behaviour at 2 months cycles during a year. Stock return, on the other hand, does not show any stochastic trend but follows persistent seasonal trend at 2, 4 and 6 months cycles during a year. The stock returns are affected by seasonal unit roots or stochastic seasonality. This suggests that the stochastic elements may have permanent effects on the seasonal pattern of stock return. These stochastic elements do not die out fast enough and their effects are transmitted to future values of the seasons.

As the monthly series of stock return contains no unit root at frequency 0 and unit root presents at frequencies $\frac{\pi}{3}$ and $\frac{\pi}{2}$ frequencies, but the series of industrial growth, inflation and call money rate have unit root at frequency 0 , cointegration relationship between stock return and real sector variables might give inconsistent results. For that reason estimation of unrestricted VAR may be appropriate in finding out the nature of interaction between stock return, industrial growth and inflation.

\section{Estimating VAR and Testing Granger Causality}

The reduced form VAR contains 4 equations for industrial growth, inflation, stock return and interest rate as dependent variables. To examine the nature of transmission we perform Granger causality test of each variable in the VAR individually and all added variables jointly. The optimum lag length is determined at 2 of the VAR with 4 variables on the basis of AIC, HQIC and SBIC criteria (Table 1A). The coefficients of the reduced form VAR are estimated by applying OLS which are shown in Table 2 and the estimated statistics for Granger causality test based on this estimated VAR are shown in Table 3 .

The estimated values of $R^{2}$ and $\chi^{2}$ statistics shown at the bottom of Table 2 confirmed that the VAR equations excepting for stock return as dependent variable are good fitted. The estimated coefficients of the equation with industrial growth as dependent variable in the VAR system shows that the return has positive impact on growth although the strength of the impact is very low. Higher return on financial asset induces higher growth. The relationship between past inflation and current growth is fairly significant. The coefficients of inflation in one period back is positive, while that for two period lag is negative. Higher the inflation in recent past, higher will be the growth. The response of growth to inflation is also positive. Stock return, on the other hand, is not affected significantly by industrial growth, but is affected inversely by inflation supporting the hypothesis put forward by Fama (1981). The negative coefficient of inflation in 1 period lag implies that rational investors can adjust asset returns on the basis of inflationary trend.

In stock return equation the coefficient of industrial growth is statistically insignificant and its sign implies the relationship goes the wrong way. But it may not be unusual in a transitional developing economy where higher economic growth does not always imply higher stock returns. The stock return indicates financial claims on the real assets of an economy. The rate of return to real assets depends on their productivity which is determined collectively by capital, labour, technology and institutions. The neoclassical growth model predicts that higher growth caused by the increases in total factor productivity will raise the rate of return to capital. But, if capital led economic growth is driven by the increase in savings, not by the total factor productivity growth, as experienced by the fast growing transitional developing economies (Krugman, 1994), the rate of return will be diminishing.

We have carried out Granger causality test after estimating the VAR. In Table 3, the row with excluded

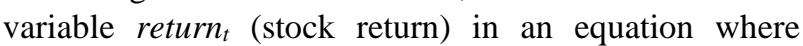
industrial growth, $g_{t}^{\text {ind }}$, is taken as a dependent variable, for example, tests the null hypothesis that all coefficients on lags of the variable stock return in the industrial growth equation are equal to zero, against the alternative that at least one is not equal to zero. On the basis of estimated $\chi^{2}$ statistic, we reject the null hypothesis that lags of the stock return rate have no effect on the industrial growth rate. Thus, in the estimated VAR model, the stock return has causal effect on industrial growth in Granger sense, although the magnitude of this effect is very low (Table 2). By contrast, in the stock return equation, we fail to reject the hypothesis that industrial growth has no effect on stock return. Thus, industrial growth does not Granger cause stock return. In stock return equation, inflation has significant causal effect, but industrial growth has no significant effect in Granger's sense. 
Table 2: Estimated coefficients of VAR

\begin{tabular}{|c|c|c|c|c|}
\hline & $g_{t}^{\text {ind }}$ & $\inf f_{t}$ & return $_{t}$ & int \\
\hline Intercept & $0.005 * * *$ & $0.004 * * *$ & $388.54 * * *$ & $1.70 * * *$ \\
\hline$g_{t-1}^{\text {ind }}$ & $0.44 * * *$ & $0.03 * *$ & -242.90 & -5.31 \\
\hline$g_{t-2}^{\text {ind }}$ & $0.40 * * *$ & -0.002 & 695.61 & $11.16^{* *}$ \\
\hline $\inf f_{t-1}$ & $0.36 * *$ & $1.32 * * *$ & $-12543.5 * *$ & -7.58 \\
\hline $\inf _{t-2}$ & $-0.36 * *$ & $-0.37 * * *$ & $10612.4 * *$ & 14.33 \\
\hline return $_{t-1}$ & $0.000004 * *$ & -0.0000004 & -0.03 & -0.00008 \\
\hline return $_{t-2}$ & 0.000002 & -0.0000006 & $-0.10 *$ & 0.000005 \\
\hline int $_{t-1}$ & $0.001 * * *$ & $-0.0003 * *$ & -1.05 & $0.47 * * *$ \\
\hline int $_{t-2}$ & $-0.0003 * * *$ & -0.00008 & -24.81000 & $0.20 * * *$ \\
\hline$R^{2}$ & 0.6526 & 0.95100 & 0.03110 & 0.4329 \\
\hline$\chi^{2}$ & 565.4837 & 5840.03700 & 9.64969 & 229.7920 \\
\hline Prob $>\chi^{2}$ & 0.0000 & 0.00000 & 0.29050 & 0.0000 \\
\hline
\end{tabular}

Source: As for Table 1

Table 3: Estimated statistics for Granger causality test

\begin{tabular}{|c|c|c|c|c|}
\hline Equation with endogenous variable & Variables excluded & $\chi^{2}$ & Degrees of freedom & Prob $>\chi^{2}$ \\
\hline \multirow[t]{4}{*}{$g_{t}^{\text {ind }}$} & $\inf f_{t}$ & 4.40040 & 2 & 0.111 \\
\hline & return $_{t}$ & 7.43730 & 2 & 0.024 \\
\hline & $i n t_{t}$ & 2.17660 & 2 & 0.337 \\
\hline & all & 12.88400 & 6 & 0.045 \\
\hline \multirow[t]{4}{*}{$\inf f_{t}$} & $g_{t}^{\text {ind }}$ & 7.35820 & 2 & 0.025 \\
\hline & return $_{t}$ & 1.89850 & 2 & 0.387 \\
\hline & int $_{t}$ & 8.93330 & 2 & 0.011 \\
\hline & all & 15.57800 & 6 & 0.016 \\
\hline \multirow[t]{4}{*}{ return $_{t}$} & $g_{t}^{\text {ind }}$ & 0.19430 & 2 & 0.907 \\
\hline & $i n f_{t}$ & 5.25650 & 2 & 0.072 \\
\hline & int $_{t}$ & 2.89880 & 2 & 0.235 \\
\hline & all & 7.75110 & 6 & 0.257 \\
\hline \multirow[t]{4}{*}{ int $_{t}$} & $g_{t}^{\text {ind }}$ & 4.70600 & 2 & 0.095 \\
\hline & $i n f_{t}$ & 2.48550 & 2 & 0.289 \\
\hline & return $_{t}$ & 0.25222 & 2 & 0.882 \\
\hline & all & 9.23680 & 6 & 0.161 \\
\hline
\end{tabular}

Source: As for Table 1

In Table 3, the row showing all variables excluded for each equation excludes all lags in the respective equation. This row shows test statistics for joint test of all lags of all independent variables in each equation. It considers a test of purely autoregressive specification a null hypothesis against the VAR specification for that equation as alternative. This joint test indicates that the VAR specification used in this study is statistically significant. The estimated results suggest that the equations for industrial growth and inflation rate are significant, while those for stock return and call money rate are purely autoregressive.

The empirical exercise in this study highlights that stock return has significant positive causal effect on industrial growth although the strength of the effect is very low. This result supports the empirical regularity as observed in developed economies by following the hypothesis put forward in (Fama, 1981). But industrial growth has no significant effect on stock return in Granger sense. Higher inflation causes lower stock return, but stock return has no effect of transmission to inflation. Although inflation in 1 period lag has positive effect on industrial growth, the inflationary effect in 2 period lag on growth is negative.

Now we evaluate the estimated VAR by stimulating some shocks to the system and trace out the effects of those shocks on endogenous variables. Figure 2 displays impulse response function for asset return and industrial growth as well as asset return and inflation. As shown in upper left panel, the impulse on industrial growth has a very short living effect on asset return. The upper right panel of Fig. 2 highlights that an increase in the orthogonalised shock to stock return causes an increase in industrial growth that does not die out even after ten periods. Similarly, the right bottom part of Fig. 2 suggests that a similar shock to inflation causes a decrease in stock return, but this effect dies out after a short period. The bottom left part shows that any shock to stock return has no significant transmission to inflation rate. 


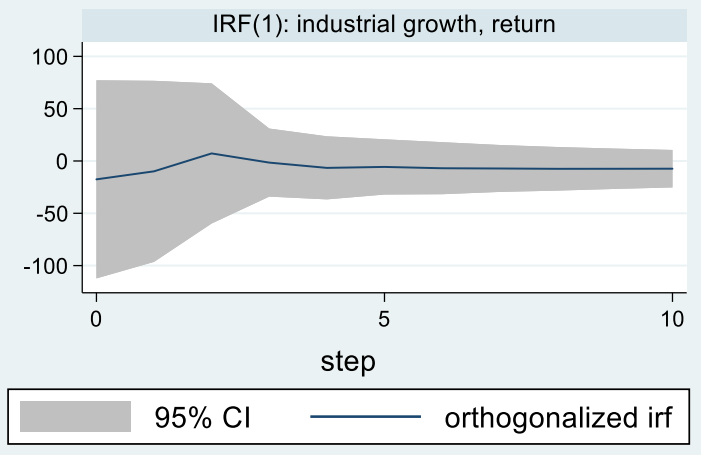

Graphs by irfname, impulse variable, and response variable

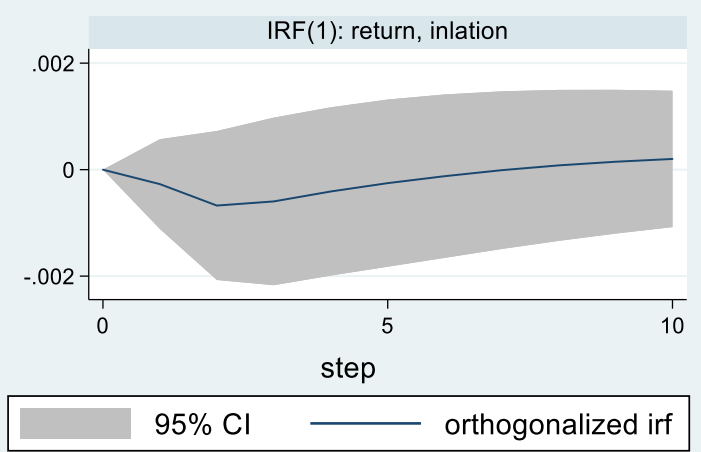

Graphs by irfname, impulse variable, and response variable

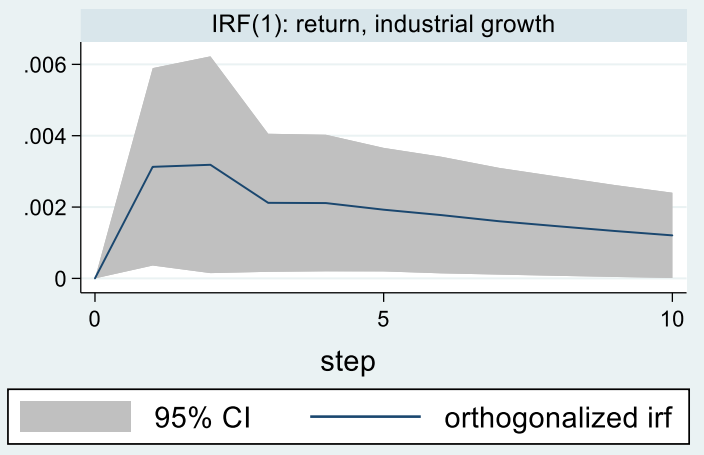

Graphs by irfname, impulse variable, and response variable

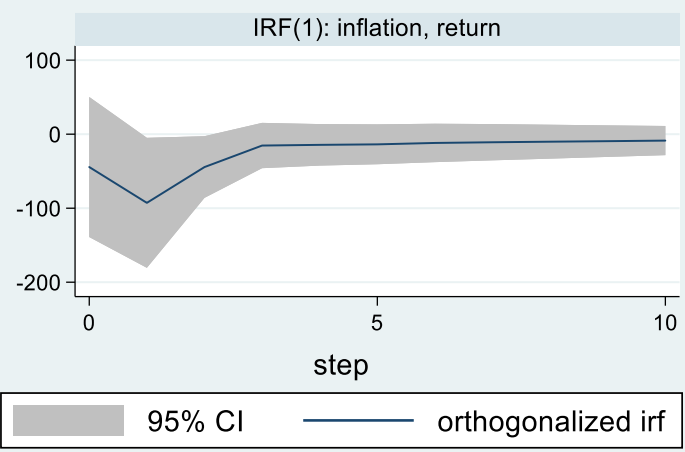

Graphs by irfname, impulse variable, and response variable

Fig. 2: Impulse response function. Source: As for Table 1

\section{Multivariate GARCH Estimation}

Stock market volatility that creates risks is expected to have significant effects on market performance of firms listed in Bombay Stock Exchange and these effects may be transmitted to the real sector. Thus volatility in asset return and time dependent conditional variance of other macroeconomic variables may have effects on the conditional mean return along with growth and inflation. In this section we analyse the behaviour of conditional variance function of the variables used in this study and examine how the relationship between stock return and growth is affected in presence of heteroschedastic behaviour of the variables. Table 4 presents the estimated coefficients of the conditional mean function with similar specification as used in the VAR model and conditional variance function in GARCH $(1,1)$ specification in a multivariate framework. The middle panel of Table 4 confirms that GARCH (1) effect is significant in all series. The ARCH (1) effect is also significant in all series excepting for inflation rate. Correlation coefficients between the variables in presence of volatility are shown at the bottom part of Table 4 . The type of relationship between stock return and growth and between stock return and inflation are similar to that predicted in the literature. The estimated coefficients shown in the upper panel of Table 4 also suggest that stock return has positive effect on growth and negative effect on inflation.

\section{Possible Explanations of Business Cycles}

To find out whether asset return leads to business cycle we use cross-correlation functions between asset return $\left(x_{1}\right)$ and growth $\left(x_{2}\right)$ :

$$
r_{12}^{k}=\operatorname{corr}\left(x_{1 t}, x_{2, t-k}\right)=\frac{r_{12}^{k}}{\sqrt{r_{11}^{0} r_{22}^{0}}}
$$

The lag length, $k$, in the correlation function may be positive or negative. Positive $k$ corresponds to correlations between asset return and past period growth, while negative $k$ provides the correlation between asset return and future growth.

This function is not symmetric about lag zero:

$$
r_{12}^{k} \neq r_{12}^{-k}
$$


Here, $r_{11}^{k}$ and $r_{22}^{k}$ are the autocorrelation functions for $x_{1}$ and $x_{2}$, respectively.

Figure 3 shows the sample cross-correlation function for stock return and the monthly growth rate of industrial production. The part left to 0 lag provides correlation between current return and future industrial growth, while the right part gives correlation coefficients between current return and past growth of industrial production. The absolute values of the cross correlation are very low (negative at the left part and positive at the right part) indicating very weak relation between asset return and industrial growth. The highest correlation $(-0.14)$ appears at negative lag length 3 suggesting that higher than average returns lead to lower than average industrial growth 3 months later. Again, the highest correlation (0.21) at positive lag length 9 implies that higher than average industrial growth leads to higher than average asset return 9 months later.

The cross correlations between asset return and inflation as shown in Fig. 4 both at nearer negative and positive lags are negative suggesting that higher than average returns lead to lower than average inflation rates and vice versa.

The changing behaviour of the cross-correlations between asset returns and growth clearly suggests a cyclical pattern showing that changes in economic growth are preceded by changes in asset returns, but in a very weak way.

It is believed in the theoretical literature that economic growth has positive effect on stock returns. This belief holds that investment in stocks of countries with stable and faster growth makes sense. It may be easier to raise equity finance by the firm when stock price rises. In this way additional investment induced by rising stock price or higher returns improves economic growth. Rise in stock returns also bring about a wealth effect, which increases aggregate consumption demand raising output growth through multiplier effect. However, there is no guarantee that the real economy influences the financial market or the other way round. We have shown that stock return has very small effect on growth and growth has no significant effect on asset return. Table 4 reveals that the correlation between asset return and industrial growth is very close to 0 . This empirical findings make it clear that there is very little connection between economic growth and stock market returns in a transitional developing economy like India.

The empirical findings of this study may be justified when behaviour of the investors in the financial market is over optimistic. If growth expectations are very high, financial assets are overpriced leading to low return in the future. Sometimes international operations of the corporations are responsible for this over optimistic behaviour and weak relation between stock return and growth. Tata Motors in India, for example, operate outside the country in the name of JLR which generates a large part of Tata's profit. In this example, JLR's operations do not add to India's growth, but its profit contribution has impact on Tata's share price.

The Indian economy has experienced a radical structural change since the early $1990 \mathrm{~s}$ and the behaviour of Sensex fails to capture all such changes of the real economy. This is because significant drivers of economic growth in the Indian economy are in the unorganised sector which do not participate in the financial market like Bombay Stock Exchange. Thus, their contribution to GDP is not reflected in the stock return.

Table 4: presents the estimated coefficients for the mean or variance equations

\begin{tabular}{|c|c|c|c|c|}
\hline & $g_{t}^{\text {ind }}$ & $\inf _{t}$ & return $_{t}$ & int $_{t}$ \\
\hline \multicolumn{5}{|l|}{ Conditional mean } \\
\hline Intercept & $0.0072^{*}$ & $0.005^{* * *}$ & 80.13 & $0.09^{* * *}$ \\
\hline int $_{t-1}$ & 0.0006 & $-0.0003^{*}$ & 5.81 & $0.72^{* * *}$ \\
\hline int t$_{t-2}$ & -0.0004 & $-0.0001^{* * *}$ & -9.46 & $0.24^{* * * *}$ \\
\hline return $_{t-1}$ & $0.000003^{* *}$ & -0.0000003 & -0.022 & $0.00002^{* * *}$ \\
\hline return $_{t-2}$ & $0.000003^{*}$ & -0.0000005 & -0.002 & $0.00004^{* * *}$ \\
\hline $\inf f_{t-1}$ & $0.30^{* *}$ & $1.34^{* * * *}$ & $-9385.46^{* * * *}$ & $-3.37^{* * * *}$ \\
\hline $\inf _{t-2}$ & $-0.29^{* *}$ & $-0.40^{* * *}$ & $8310.46^{* * *}$ & $5.45^{* * *}$ \\
\hline$g_{t-1}^{\text {ind }}$ & $0.41^{\text {**** }}$ & 0.021 & 363.18 & $1.28^{* * *}$ \\
\hline$g_{t-2}^{\text {ind }}$ & $0.43^{* * *}$ & 0.003 & 33.87 & $1.43^{* * * *}$ \\
\hline \multicolumn{5}{|c|}{ Conditional variance } \\
\hline Intercept & 0.000008 & $0.00008^{* * * *}$ & 1406.13 & -0.000003 \\
\hline $\mathrm{ARCH}(1)$ & $0.09^{* * *}$ & 0.09 & $0.20^{* * *}$ & $4.65^{* * *}$ \\
\hline GARCH (1) & $0.90^{* * * *}$ & $-0.46^{* * *}$ & $0.83^{* * *}$ & $0.14^{* * *}$ \\
\hline Corr $\left(\right.$ int $_{t}$, return $\left._{t}\right)$ & -0.044 & $\operatorname{corr}\left(\right.$ return $_{t}$, inf $\left._{t}\right)$ & -0.062 & \\
\hline Corr $\left(\right.$ int $t_{t}$, inf $\left._{t}\right)$ & 0.093 & $\operatorname{corr}\left(\right.$ return $\left._{t}, g_{t}^{\text {ind }}\right)$ & 0.008 & \\
\hline Corr (int $\left.t, g_{t}^{\text {ind }}\right)$ & -0.020 & $\operatorname{corr}\left(i n f_{t}, g_{t}^{\text {ind }}\right)$ & 0.013 & \\
\hline
\end{tabular}

Source: As for Table 1 


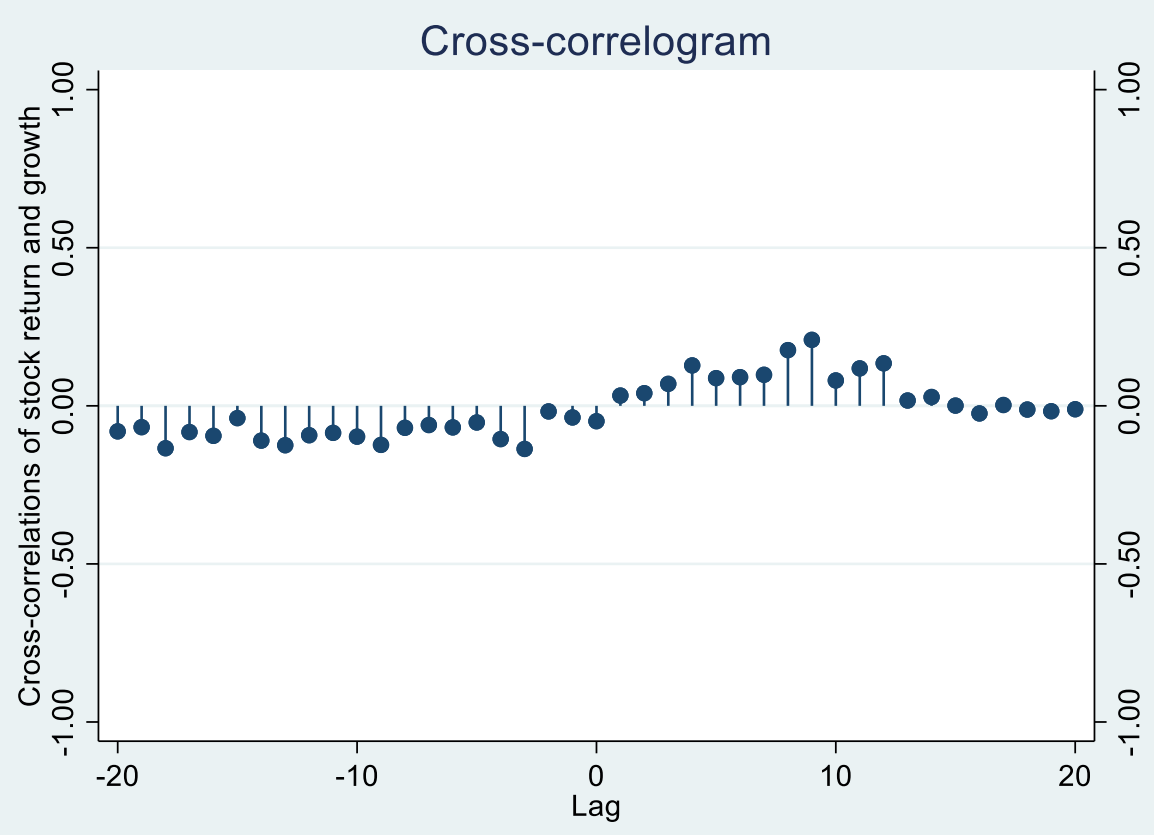

Fig. 3: Cross correlation between asset return and growth. Source: As for Table1

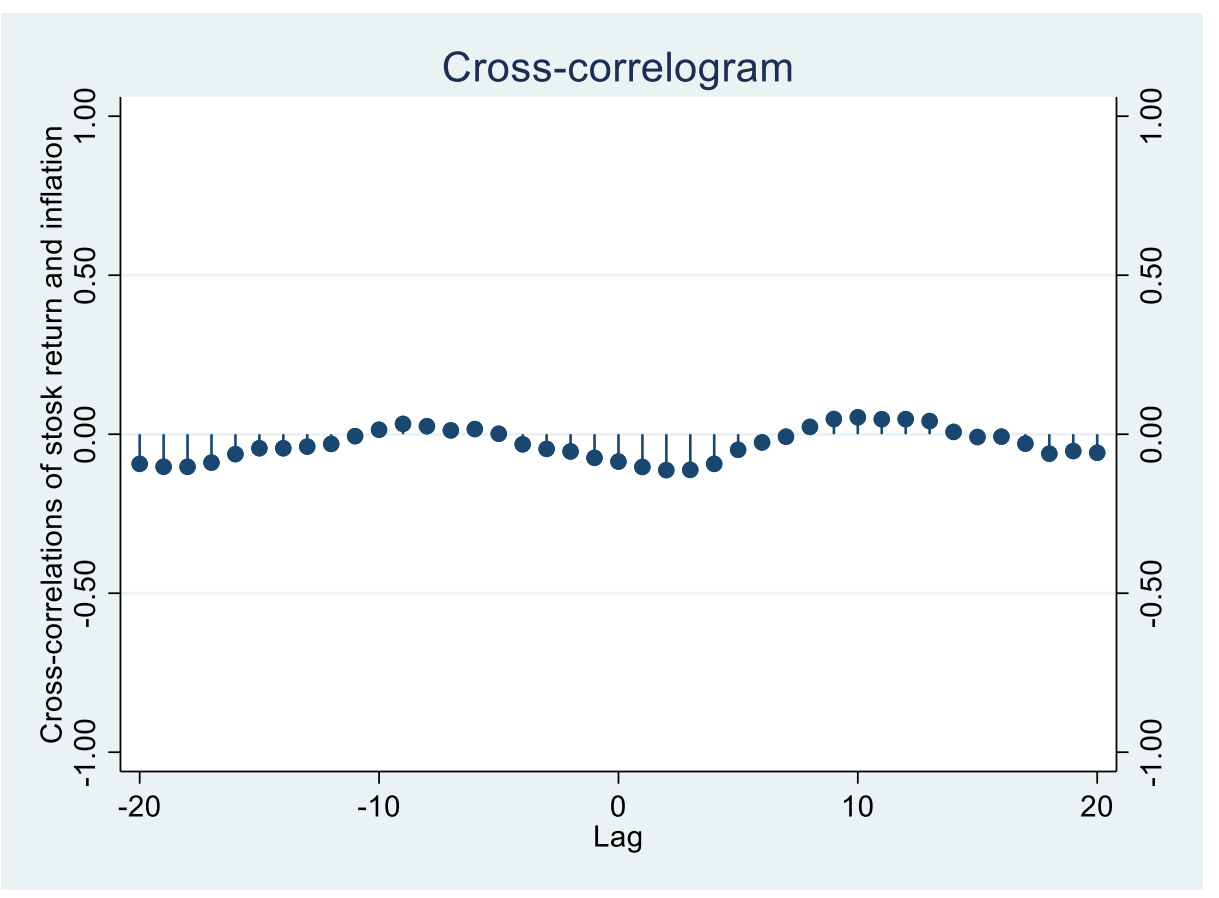

Fig. 4: Cross correlation between asset return and inflation. Source: As for Table1

\section{Conclusion}

This study examines the relation between return from the financial assets and industrial growth with monthly time series data from India by looking into stochastic seasonality and the behaviour of volatility clustering of the variables.
The objective is to reconcile the dynamics observed in a transitional developing economy with the empirical regularities as observed in the literature based on data from the developed world. We have looked into whether the shocks in stock returns have had any effect on industrial growth and inflation and, also how 
the stock returns response to innovations in the real sector in the context of financial sector reforms in India. The primary objective of this study is to find out the causality between stock return and industrial growth. If causality goes from stock return to industrial growth then it has policy implications particularly in the context of financial sector reforms.

The study observes that industrial growth, inflation and call money rate exhibit non-seasonal unit roots at zero frequency representing long run stochastic trend, while stock return exhibits no unit root at frequency zero suggesting that the series has no pure trend. The absence of zero frequency unit root in the monthly series of stock return is consistent with the market efficiency hypothesis. The HEGY unit root test suggests that industrial growth and inflation experience only stochastic trend and no persistent stochastic behaviour at any other seasonal frequencies. Stock return follows persistent seasonal trend at 2, 4 and 6 months cycles during a year.

The empirical exercise in this study also highlights that stock return has positive causal effect on industrial growth although the effect is very weak. While this result supports the empirical regularity as observed in developed economies by following the hypothesis put forward in (Fama, 1981), the very weak relationship is justified by the dominance of the unorganised sector in industrial production. However, industrial growth has no significant effect on stock return in Granger sense. Higher inflation causes lower stock return, but stock return has no effect of transmission to inflation. Although inflation in 1 period lag has positive effect on industrial growth, the inflationary effect in 2 period lag on growth is negative.

A very weak cyclical relationship between stock returns and industrial growth raises major questions about the role of financial development in enhancing economic growth in India. To understand why stock return from BSE Sensex fails to capture fully the dynamism of the real sector of the Indian economy we need to look into the structure and composition of Sensex and sectoral composition of GDP. In Sensex, financial services accounts for $37.6 \%$, while in national accounts the contribution of this sector is around 20 percent implying that financial services seems to be significantly over represented in Sensex.

\section{Acknowledgment}

Author is grateful to the reviewers for their comments and is also indebted to the publishing authority for considering the article for publication.

\section{Ethics}

All rights of this study are owned by the author at the Department of Economics, University of Calcutta and should be maintained.

\section{References}

Acharya, D., Amanulla, S., \& Joy, S. (2009). Financial development and economic growth in Indian states: An examination. International Research Journal of Finance and Economics, 24(2), 117-130.

Alam, M. I., \& Hasan, T. (2003). The causality between stock market development and economic growth: Evidence from the United States. Studies in Economics and Finance. https://www.emerald.com/insight/content/doi/10.11 08/eb028770/full/html

Bagehot, W. (1873). Lombard Street, Homewood, IL: Richard D. Irwin, (1962 Edition).

Beaulieu, J. J., \& Miron, J. A. (1993). Seasonal unit roots in aggregate US data. Journal of Econometrics, 55(1-2), 305-328. doi.org/10.1016/0304-4076(93)90018-Z

Bhattacharya, P. C., \& Sivasubramanian, M. N. (2003). Financial development and economic growth in India: 1970-1971 to 1998-1999. Applied Financial Economics, 13(12), 925-929. doi.org/10.1080/0960310032000129590

Bhowmik, R., \& Wang, S. (2020). Stock Market Volatility and Return Analysis: A Systematic Literature Review. Entropy. 22(5), 522. doi.org/10.3390/e22050522

Bollerslev, T. (1990) Modeling the Coherence in ShortRun Nominal Exchange Rates: A Multivariate Generalized ARCH Model. Review of Economics and Statistics, 72: 498-505. doi.org/10.2307/2109358

Brasoveanu, L. O., Dragota, V., Catarama, D., \& Semenescu, A. (2008). Correlations between capital market development and economic growth: The case of Romania. Journal of Applied Quantitative Methods, 3(1), 64-75.

https://citeseerx.ist.psu.edu/viewdoc/download?doi= 10.1.1.475.5979\&rep=rep1\&type=pdf

Dailami, M., \& Atkin, M. (1990). Stock markets in developing countries: Key issues and a research agenda (Vol. 515). World Bank Publications.

de Pablo Valenciano, J., Mesa, J. C. P., \& Mangin, J. P. L. (2008). The Spanish tomato export sector of the Almeria region: An econometric approach. International Advances in Economic Research, 14(3), 316-328. doi.org/10.1007/s11294-008-9155-X

Deb, S. G., \& Mukherjee, J. (2008). Does stock market development cause economic growth? A time series analysis for Indian economy. International Research Journal of Finance and Economics, 21(3), 142-149. https://memberfiles.freewebs.com/99/21/62292199/ documents/irjfe_21_12.pdf 
Diamond, P. A. (1965). National debt in a neoclassical growth model. The American Economic Review, 55(5), 1126-1150.

https://www.jstor.org/stable/1809231

El-Wassal, K. A. (2005). Understanding the growth in emerging stock markets. Journal of Emerging Market Finance, 4(3), 227-261. https://doi.org/10.1177/097265270500400302

Fama, E. F. (1981). Stock returns, real activity, inflation and money. The American Economic Review, 71(4), 545-565. https://www.jstor.org/stable/1806180

Franses, P. H. (1991). Seasonality, non-stationarity and the forecasting of monthly time series. International Journal of Forecasting, 7(2), 199-208. doi.org/10.1016/0169-2070(91)90054-Y

Geske, R. L., \& Roll, R. (1983). R The Monetary and Fiscal Linkage between Stock Returns and Inflation. Journal of Finance, 1. doi.org/10.1111/j.1540-6261.1983.tb03623.x

Goldsmith, R. W. (1959). Financial Structure and Development as a Subject for International Comparative Study.

Goodwin, R. M. (1967). A growth cycle. Socialism, capitalism and economic growth. Fenstein (Ed). pp, 165-170 https://link.springer.com/chapter/10.1007/978-1349-05504-3_12

Gupta, A. D., \& Padhan, P. C. (2007). The nexus between stock market and economic activity: An empirical analysis for India. International Journal of Social Economics.

https://www.emerald.com/insight/content/doi/10.11 08/03068290710816874/full/html

Har, W. M., Ee, C. S., \& Tan, C. T. (2008). Stock market and economic growth in Malaysia: Casuality test. Asian Social Science, 4(4), 86-92. doi.org/10.5539/ass.v4n4p86

Hess, P. J., \& Lee, B. S. (1999). Stock returns and inflation with supply and demand disturbances. The Review of Financial Studies, 12(5), 1203-1218. doi.org/10.1093/rfs/12.5.1203

Hicks, J. (1969). A theory of economic history (Vol. 9). Oxford: Oxford University Press.

Hylleberg, S., Engle, R. F., Granger, C. W., \& Yoo, B. S. (1990). Seasonal integration and cointegration. Journal of Econometrics, 44(1-2), 215-238. doi.org/10.1016/0304-4076(90)90080-D

Kaldor, N. (1940). A model of the trade cycle. The Economic Journal, 78-92. doi.org/10.2307/2225740

Kalecki, M. (1968). Trend and business cycles reconsidered. The Economic Journal, 78(310), 263-276. doi.org/10.2307/2229463

Kim, S., \& In, F. (2005). The relationship between stock returns and inflation: New evidence from wavelet analysis. Journal of Empirical Finance, 12(3), 435-444. doi.org/10.1016/j.jempfin.2004.04.008
Krugman, P. (1994). The myth of Asia's miracle. Foreign Affairs, 62-78. doi.org/10.2307/20046929

Lee, B. S. (1992). Causal relations among stock returns, interest rates, real activity and inflation. The Journal of Finance, 47(4), 1591-1603. doi.org/10.1111/j.1540-6261.1992.tb04673.x

Levine, R. (1991). Stock markets, growth and tax policy. The Journal of Finance, 46(4), 1445-1465. doi.org/10.1111/j.1540-6261.1991.tb04625.x

Levine, R., \& Zervos, S. (1996). Stock market development and long-run growth. The World Bank Economic Review, 10(2), 323-339. doi.org/10.1093/wber/10.2.323

Lucas Jr, R. E. (1988). On the mechanics of economic development. Journal of Monetary Economics, 22(1), 3-42. doi.org/10.1016/0304-3932(88)90168-7

Marshall, D. A. (1992). Inflation and asset returns in a monetary economy. The Journal of Finance, 47(4), 1315-1342. doi.org/10.1111/j.1540-6261.1992.tb04660.x

Mugambe, G. K., \& Reilly, B. (2007). Seasonality and industrial production in Uganda. African Development Review, 19(3), 501-518. doi.org/10.1111/j.1467-8268.2007.00173.x

Nagaraj, R. (1996). India's capital market growth: Trends, explanations and evidence. Economic and Political Weekly, 2553-2563. https://www.jstor.org/stable/4404573?seq=1

Obstfeld, M. (1992). Risk-taking, global diversification and growth (No. w4093). National Bureau of Economic Research. doi.org/10.3386/w4093

Oskooe, S. A. (2010). Emerging stock market performance and economic growth. American Journal of Applied Sciences, 7(2), 265. doi.org/10.3844/ajassp.2010.265.269

Ramsey, F. P. (1928). A mathematical theory of saving. The Economic Journal, 38(152), 543-559. doi.org/10.2307/2224098

RBI. (2020). Handbook of Statistics on Indian Economy, Reserve Bank of India

Robinson, J., (1952), The Rate of Interest and Other Essays, Macmillan, London.

Solow, R. M. (1956). A contribution to the theory of economic growth. The Quarterly Journal of Economics, 70(1), 65-94. doi.org/10.2307/1884513

Stiglitz, J. E. (1993). The role of the state in financial markets. The World Bank Economic Review, 7(suppl_1), 19-52. doi.org/10.1093/wber/7.suppl_1.19

Taylor, A. R. (1998). Testing for unit roots in monthly time series. Journal of Time Series Analysis, 19(3), 349-368. doi.org/10.1111/1467-9892.00096 
Vazakidis, A., \& Adamopoulos, A. (2011). Credit market development and economic growth an empirical analysis for greece. American Journal of Applied Sciences, 8(6), 584.

doi.org/10.3844/ajassp.2011.584.593 von Arnim, R., \& Barrales, J. (2015). Demand-driven Goodwin cycles with Kaldorian and Kaleckian features. Review of Keynesian Economics, 3(3), 351-373.

doi.org/10.4337/roke.2015.03.05

\section{Appendix}

Table 1A: Lag selection criteria

\begin{tabular}{|c|c|c|c|c|c|c|c|c|}
\hline lag & LL & LR & $\mathrm{df}$ & $\mathrm{p}$ & FPE & AIC & HQIC & SBIC \\
\hline 0 & -1832.01 & & & & 6.1095300 & 13.1614 & 13.18220 & 13.21340 \\
\hline 1 & -1281.80 & 1100.4000 & 16 & 0.000 & 0.1327050 & 9.33187 & 9.43629 & 9.59217 \\
\hline 2 & -1209.66 & 144.2800 & 16 & 0.000 & $.0088746^{*}$ & $8.92944 *$ & $9.1174 *$ & $9.39799 *$ \\
\hline 3 & -1195.35 & 28.6240 & 16 & 0.027 & 0.0898430 & 8.94154 & 9.21304 & 9.61833 \\
\hline 4 & -1185.75 & 19.1930 & 16 & 0.259 & 0.0940950 & 8.98745 & 9.34248 & 9.87248 \\
\hline 5 & -1176.73 & 18.0410 & 16 & 0.322 & 0.0989750 & 9.03748 & 9.47604 & 10.13080 \\
\hline 6 & -1171.92 & 9.6213 & 16 & 0.886 & 0.1073260 & 9.11769 & 9.63979 & 10.41920 \\
\hline 7 & -1162.07 & 19.7010 & 16 & 0.234 & 0.1122850 & 9.16178 & 9.76741 & 10.67150 \\
\hline 8 & -1151.70 & 20.7380 & 16 & 0.189 & 0.1170780 & 9.20214 & 9.89131 & 10.92010 \\
\hline 9 & -1135.55 & 32.2920 & 16 & 0.009 & 0.1171700 & 9.20109 & 9.97380 & 11.12730 \\
\hline 10 & -1120.61 & 29.8800 & 16 & 0.019 & 0.1183340 & 9.20869 & 10.06490 & 11.34320 \\
\hline
\end{tabular}

Source: As for Table 1 